\title{
Assessment of severity scores in community-acquired pneumonia for adult patients- A cross-sectional study
}

\author{
Chandra Shekhar Purohot ${ }^{1}$, Kalpesh Patel ${ }^{2, *}$ \\ ${ }^{1,2}$ Assistant Professor, Dept. of Tuberculosis and Respiratory Medicine, ${ }^{1}$ Shri Ram Murti Smarak Institute of Medical Sciences, \\ Bareilly, Uttar Pradesh, ${ }^{2}$ Gujarat Adani Institute of Medical Sciences, Bhuj, Kutch, Gujarat, India
}

*Corresponding Author:

Email: researchguide86@gmail.com

\begin{abstract}
Background: Current research was carried out to evaluate the severity score such as PSI, SMART-COP and CURB-65 for the capability to forecast the requirement for mechanical ventilation and inotropic support for adult patients.

Materials and Methods: Current observational research was carried out in subjects admit with CAP. The evaluation utensils utilized were the CURB-65 score, PSI, and the SMART-COP scores, particularly planned to forecast the necessity for intensive respiratory and vasopressor support. In general result with CAP was too evaluated.

Results: Statically significant was observed in sensitivity and specificity for CURB-65scoresinmechanical ventilation and inotropic support. Fifty nine participants have been mandatory required mechanical ventilation and 41 preferred inotropic supports during their hospital stay.

Conclusions: CURB 65 and PSI scores, even if extensively utilized for forecasting death in big inhabitants, they are not as much of precise for forecasting results.
\end{abstract}

Keywords: Community-acquired pneumonia; Cross-sectional study; Sensitivity; Specificity.

\section{Introduction}

Infection of lung parenchyma is called as pneumonia. CAP fluctuates from the pneumonia that is obtain in hospital, so that's why called as hospital acquired pneumonia[1-3]. The main causative organism for CAP is bacteria and they have been classified as atypical and typical pneumonia. The main causative organism are staphylococcus aureus, haemophilius influenza and streptococcus pneumonia. Other atypical causative pathogens like Mycoplasma pneumonia, Chlamydophilia species are in frequently recognized as we require special lab analysis for their identification and diagnosis $[4,5]$.

The clinical features CAP are cough, sputum, dyspnea, rigors, chills and chest discomfort. However in many cases some of the patients do satisfy the above present criteria but instead of pneumonia they might have acute bronchitis. Due to inability of differentiation from bronchitis and pneumonia there is the over use of the antibiotics. Many times in the patient analyzed with CAP, there may be present with fever without localizing features that may add to the mortality and morbidity in the adult patients. The treatment regimens for the CAP depend on the assessment of the strictness of the illness. Either to treat with antibiotic regime or requires hospitalization for further treatment depends on the severity of diseases. To avoid such situation there are development of the prediction rules that helps in assisting the treatment protocol. The forecast regulates that are most frequently utilized are pneumonia confusion, severity index, age more than 65 years, respiratory rate, tachycardia, vasopressor support and requirement of ventilator. Therefore, current research was carrying out to evaluate the score such as
PSI, SMART-COP and CURB-65 for adult patients indoor in hospital with CAP.

\section{Materials and Methods}

The present study was conducted at the Department of Respiratory Medicine, Gujarat Adani Institute of Medcial Science, Bhuj, Kutch on indoor patients identified with CAP. Prior to the conduction of the study, the review board of the medical centres were informed and ethical approval was taken from them. The informed consent was taken from all the participants who were willing to participate in the study. The inclusion criteria are as follows: present and development of more than 3 symptoms. Symptoms include dyspnea, chest pain, fever, headache, hemoptysis and presence of productive cough. The exclusion criteria were the presence of hospital acquired pneumonia, immunocompromised persons and active thoracic malignancy. A proforma was arranged and finished during hospital admittance. Patient's vital and standard blood tests were analyzed. Requirement for mechanical ventilation and/or inotropic support were utilized to estimate the requirement of intensive respiratory, vasopressor support and to assess mortality for adult patients admitted with CAP. In general result of patients with CAP was too evaluated.

\section{Statistical analysis}

Microsoft excel spreadsheet was use for data collection and coding. SPSS version 15 was utilized to do the analysis. The variables were assessed for normality using the Kolmogorov-Smirnov test. Descriptive statistics were calculated. 


\section{Results}

There were $59 \%$ were male and $41 \%$ female in the study population with renal and congestive heart disease were key co-morbidities. The sensitivity and specificity for CURB-65 were significantly higher in
Class 2 [Table $2 \mathrm{a}$ and $\mathrm{b}$ ]. Fifty nine patients required mechanical during their hospital stay. It was shown that SMART-COP is an improved forecasting utensil contrast to CURB-65 and PSI in predicting mechanical ventilation and inotropic support.

Table 1: The comorbidities in patients admitted with community acquired pneumonia

\begin{tabular}{|l|c|}
\hline \multicolumn{1}{|c|}{ Diseases } & $\begin{array}{c}\text { Number of } \\
\text { patients }\end{array}$ \\
\hline Neoplastic disease & 1 \\
\hline Cerebrovascular disease & 7 \\
\hline Chronic liver disease & 20 \\
\hline $\begin{array}{l}\text { Congestive cardiac } \\
\text { failure }\end{array}$ & 24 \\
\hline Chronic renal disease & 12 \\
\hline
\end{tabular}

Table 2a: Variables for various classes of CURB-65 scoring system for predicting mechanical ventilation

\begin{tabular}{|c|c|c|c|c|}
\hline $\begin{array}{c}\text { CURB- 65 } \\
\text { class }\end{array}$ & $\begin{array}{c}\text { Sensitivity } \\
(\boldsymbol{\%})\end{array}$ & $\begin{array}{c}\text { Specificity } \\
(\boldsymbol{\%})\end{array}$ & NPV (\%) & PPV (\%) \\
\hline 2 & 85.7 & 47.5 & 9.7 & 63.3 \\
\hline 3 & 95.2 & 27.1 & 5.9 & 683. \\
\hline
\end{tabular}

Table 2b: Variables for various classes of CURB-65 scoring system for predicting inotropic support

\begin{tabular}{|c|c|c|c|c|}
\hline $\begin{array}{c}\text { CURB- 65 } \\
\text { class }\end{array}$ & $\begin{array}{c}\text { Sensitivity } \\
(\boldsymbol{\%})\end{array}$ & $\begin{array}{c}\text { Specificity } \\
(\boldsymbol{\%})\end{array}$ & NPV (\%) & PPV (\%) \\
\hline 2 & 85.4 & 64.1 & 19.4 & 28.6 \\
\hline 3 & 100 & 20.3 & 5.9 & 36.5 \\
\hline
\end{tabular}

\section{Discussion}

Evaluation of the strictness and precise diagnosis is necessary for the further decision making. Levels of the treatment and overall cost of the treatment signify it. As per the recommendation of British Thoracic Society CURB-65 is the valid method of predicting mortality in association with community acquired pneumonia[6]. Fine et al., has developed Pneumonia severity index score which includes twenty items[7]. The items include are five comorbid conditions, seven laboratory result, 5 physical examination findings and 3 demographic variables. For all item point were allocated. The total concluding score was completed and separated into five risk classes. Low risks appear beneath classes I - III which are controllable, and those who fell in class IV and class V have need of indoor facilities.

SMART-COP is necessary to evaluate the patient, that require rigorous respiratory support[8]. Mechanical ventilation got lesser significance in comparison to inotropic support as most of the patients had requirement of vasopressor support. Finding of the current research were analogous to Chalmers and Singanayagam[9]. In the present study CURB-65 and PSI similarly had low specificity and sensitivity which is analogous to study conducted by Shah et al.[10].

\section{Conclusions}

PSI and CURB 65 values are not as much of precise for forecasting of results advanced researches are obligatory in bigger community and patients which compares various prognostic tools obtainable.

Conflicts of interest: None declared.

\section{Acknowledgements}

Author wants to thank all the participants who were part of the study.

\section{References}

1. Lim WS, Baudouin SV, George RC, Hill AT, Jamieson $\mathrm{C}$, Le Jeune I, et al. BTS guidelines for the management of community acquired pneumonia in adults: Update 2009. Thorax 2009;64 Suppl 3:iii1-55.

2. Marrie TJ, Poulin-Costello M, Beecroft MD, HermanGnjidic Z. Etiology of community-acquired pneumonia treated in an ambulatory setting. Respir Med 2005;99:605.

3. Marik PE. The clinical features of severe communityacquired pneumonia presenting as septic shock. Nora sept II Study Investigators. J Crit Care 2000;15:85-90.

4. Menon RU, George AP, Menon UK. Etiology and Antimicrobial sensitivity of organisms causing community acquired pneumonia: A single hospital study. J Family Med Prim Care 2013;2:244-9.

5. Shah BA, Singh G, Naik MA, Dhobi GN. Bacteriological and clinical profile of Community acquired pneumonia in hospitalized patients. Lung India 2010;27:54-7. 
6. Community-acquired pneumonia in adults in British hospitals in 1982-1983: A survey of aetiology, mortality, prognostic factors and outcome. The British Thoracic Society and the Public Health Laboratory Service. $Q J$ Med 1987;62:195-220.

7. Fine MJ, Auble TE, Yealy DM, Hanusa BH, Weissfeld LA, Singer DE, et al. A prediction rule to identify lowrisk patients with community-acquired pneumonia. $N$ Engl J Med 1997;336:243-50.

8. Charles PG, Wolfe R, Whitby M, Fine MJ, Fuller AJ, Stirling R, et al. SMART-COP: A tool for predicting the need for intensive respiratory or vasopressor support in community-acquired pneumonia. Clin Infect Dis 2008;47:375-84.
9. Chalmers JD, Singanayagam A, Hill AT. Predicting the need for mechanical ventilation and/or inotropic support for young adults admitted to the hospital with community-acquired pneumonia. Clin Infect Dis 2008;47:1571-4.

10. Shah BA, Ahmed W, Dhobi GN, Shah NN, Khursheed SQ, Haq I. Validity of pneumonia severity index and CURB-65 severity scoring systems in community acquired pneumonia in an Indian setting. Indian J Chest Dis Allied Sci 2010;52:9-17.

How to cite this article: Purohot $\mathrm{C} \mathrm{S}$, Patel $\mathrm{K}$. Assessment of severity scores in community-acquired pneumonia for adult patients- A cross-sectional study. Indian J Immunol Respir Med. 2018;3(4):174-176. 